\title{
David Simpson steps down as News Editor
}

\section{Ruth E Malone}

Coming on the heels of the publication of Tobacco Control's Twentieth Anniversary issue (vol. 21, issue 2) comes another landmark: David Simpson is stepping down from his longtime position as editor for the journal's News Analysis section, which he has held since shortly after the journal's founding in 1992. Mr Simpson's contributions to tobacco control are legion. Many across the globe, including a number of those on our editorial board, have benefited from his mentoring, teaching, training and overall good humour in developing and working on major tobacco control initiatives over the last several decades.

After a stint at Amnesty International, Mr Simpson's career in tobacco control began as director of Action on Smoking and Health UK from 1979 to 1990. He grew the organisation's networking capacity and expanded into the field of smoking in public places, including a thennew area of interest, smoking in the workplace. Action on Smoking and Health

Correspondence to Dr Ruth E Malone, Department of Social and Behavioral Sciences, University of California, San Francisco, CA 94118, USA; ruth.malone@ucsf.edu launched a consultancy to help employers with implementation of non-smoking workplace policies. He was also involved with establishing the UK's No Smoking Day in its national form; assisting with the development of the British Medical Association's campaigns on tobacco; and running workshops on tobacco control (especially in low-income countries). He also worked to help sustain fledgling tobacco control organisations in many countries.

Internationally, he founded and served as Director of the International Agency on Tobacco and Health, serving from 1991 to 2007. The International Agency on Tobacco and Health provided information and advice on tobacco control policy issues to colleagues in countries with fewer resources. By June 2002, it had identified, registered, and was serving 251 'Contact' agencies working on this aspect of public health in 114 countries, mainly developing countries and those in Central and Eastern Europe. In addition, he served as a consultant to or member of numerous major tobacco control organisations, including the $\mathrm{WHO}$, the International Union Against Cancer, and GLOBALINK.
As News Editor, Mr Simpson worked assiduously with many inexperienced authors from low and middle-income countries to write up their news stories and fact-check them. His encouragement helped many budding authors get their start in sharing their 'on the ground' perspectives on tobacco control news, making contributions which are so valuable in building the global tobacco control community. His keen eye for the ironic detail, the colourful photograph, the industry slip-up was a great advantage to the position. He will be missed-but he has promised to continue to weigh in with the occasional scoop story or suggestion for one.

No one can fill such shoes, but Marita Hefler of University of Sydney, aided by longtime Deputy News Editor Stan Shatenstein and Web and New Media Editor Becky Freeman, will be working hard to do so. We are excited about expanding and extending the reach of the news section and will keep you apprised of developments. Meanwhile, please join us in heartily celebrating David Simpson's sustained contributions to tobacco control and to the journal. We wish him the best and can't wait to see what he tackles next. Climate change, anyone?

Contributors RM wrote the editorial.

Competing interests None.

Provenance and peer review Commissioned; internally peer reviewed.

Tobacco Control 2012;21:455.

doi:10.1136/tobaccocontrol-2012-050683 